\title{
EVALUATION OF AYURVEDIC HERB FORMULATION AS A POTENTIAL WEANING FOOD
}

\author{
Pallavi Tupkar ${ }^{1}$, Sabiha A. Vali'2 \\ 1.Dietitian, Niramaya Hospital, Chinchwad, Pune (MS) \\ 2.Ex-Professor \& HOD, Home Science Department, RTM Nagpur University, Nagpur (MS) \\ pallavitupkar@gmail.com
}

\begin{abstract}
:
Protein calorie malnutrition among infant are prevalent in many parts of India and is mainly due to inappropriate and inadequate feeding practice and ignorance of mother. Low-income population in our country cannot afford to use commercial infant food products due to financial constraints, or lack of knowledge. The most commonly used complementary food used is cow/buffalo milk followed by homemade semi-solids. Hence formulation and development of nutritious weaning foods from local and readily available raw materials has received considerable attention in many developing countries. Various texts in Ayurveda give formulas and foods for the development of the child. Ayurvedic herbs can be therefore be incorporated in weaning food formulas. The present study aimed to develop weaning food based on Ayurvedic Herbs (AH). The composition of the product formulated included Popped rice, Priyal seeds (Buchanania lanzan Spreng), Yashtimadhu (Glycyrrhiza glabra), Elaichi (Elettaria cardamomum), Shunthi (Zingiber officinale Roscoe), sugar in specific proportions. The formulated mixture was standardized to ascertain the correct proportion of ingredients and the resultant product was subjected to sensory analysis. Proximate composition, $\mathrm{pH}$, density and viscosity of the product was assessed by standard methods Results of the study reflect that Ayurvedic based infant food not only satisfies the palatability aspect but also seems to be nutrient dense which makes it a good choice for weaning food.
\end{abstract}

Key words: - Ayurvedic weaning food, density, viscosity, sensory attributes.

\section{INTRODUCTION:}

In low- and middle-income countries stunting is prevalent and contributes to high rates of morbidity and mortality in childhood and throughout the life course. Exclusive breastfeeding for 6 months after birth has many benefits for the infant and mother. The first year of life particularly the first 6 months is the most critical period in a child's life. Breast feeding is the prerequisite for child's survival throughout the critical period of life. Breast milk is adequate to meet the energy and nutrient requirements of an infant up to four to six months of age. Calories and other nutrients are needed to supplement the milk until the child is ready to eat only adult foods. At this stage, weaning is initiated. It's observed that calorie protein malnutrition among infant are prevalent in many parts of India and is mainly due to inappropriate and inadequate feeding practice and ignorance of mother.

Formulation and development of nutritious weaning foods from local and readily available raw materials has received considerable attention in many developing countries. The commercially standardized foods are generally magnificent and can help meet the nutritional requirements of young children in both developed and developing countries (7). However, the development of low-cost, highprotein food supplements for weaning infants is a constant challenge for developing countries. In India recently, several weaning products are available in market which are expensive. These 
products are not affordable by the people of lower income group. In this case majority of the infants are not fed with the right nutritional product which consequently leads to poor growth rate and in some cases the infants are malnourished. Also, as of today, there is no provision for the supply of the baby food products from the government hospitals to the infants at subsidized rate.

Ayurvedic medicine maintains its holistic approach to health and treatment of diseases. Apart from being the time-tested science that it is, Ayurveda has made its place in every household of the country through its simple readily available herbs.

Till date the supplementary food based on Ayurvedic formulation is not available in the local market. In view of this there is a need to develop a cost-effective ayurvedic infant food product which can be made from the locally available indigenous foods with minimum processing. The formulation used in this study is stated in "Ashtanghrudaya" which is one of the three main treatises of Ayurveda. It is a unique combination of laja, ("DhanLahi" in local language), sugar, priyal seeds, yashti madhu and shunthi. It is specially recommended at the stage of dentition (development of teeth in infants). Also, it is recommended as a first weaning food for infants. It is necessary to mainstream the formulations of Ayurveda as proper supplementary food for the benefit of the community and the indigenous science. The present study aimed to develop a weaning food from Ayurvedic Herbs (AH) and to estimate proximate composition, iron Magnesium and Calcium content, $\mathrm{pH}$, density and viscosity.

The need of the study arises because much of the low-income population in our country cannot afford to use commercial food products due to financial constraints, or lack of knowledge. The most commonly used complementary food was cow/buffalo milk followed by homemade semi-solids. Use of commercial food was more among literate mothers. This keeps the low- and middleincome group vulnerable to high expenses to fulfil nutritive needs. Ayurvedic formulations if researched properly and developed as per current requisites can be potential candidates for cost effective and accessible weaning food.

\section{MATERIAL \& METHODS:}

This study was carried out at Post Graduate Department of Home Science, Rashtrasant Tukadoji Maharaj Nagpur University, Nagpur, Maharashtra. The research constitutes formulation of the Ayurvedic herb (AH) product.

Product Formulation-The AH product was derived from the reference of Ashtang Hruday Uttartantra (chapter 1, verse 38). Procurement of all raw materials required for formulation of the product was done from the local market while taking care of quality and standard of the raw material. The formula of $100 \mathrm{gm}$ included popped rice $40 \mathrm{gm}$, Priyal seeds (Buchanania lanzan Spreng) 10 gm, Yashti madhu (Glycyrrhiza glabra) 10 gm, Elaichi (Elettaria cardamomum) $5 \mathrm{gm}$, Shunthi (Zingiber officinale Roscoe) $5 \mathrm{gm}$, sugar $30 \mathrm{gm}$. The product was standardized by repeated trials and subjected to sensory evaluation.

Sensory analysis: The sensory characteristics of food were evaluated following the ranking test described Ihekoronye and Ngoddy (1985). A trained panel of 10 members was assigned to evaluate the sensory attributes and palatability of the formulated food. For this study a panel of ten trained judges were chosen. An appropriate time (2pm to2.30pm) was chosen for sensory evaluation of the standardized product. Each attribute was scored based on the description ranged from superior to inferior in descending order (very good (10), good (8), fair (6) and poor (4)). A score card was prepared with sensory attributes viz: appearance, texture, mouthfeel, 
taste, and acceptability. The product was presented to the panel members with the score card for evaluation in the Food Science laboratory of Department of Home Science. Palatability evaluation of the product was done on three consecutive days. Means were derived for the attributes for three days and ten judges and overall acceptability determined.

Proximate analysis: Proximate composition (protein, ash and fat) of formulated weaning formulations was determined by Association of Official Analytical Chemists (2000) method. For determination of fibre, moisture- and fat-free sample was digested with acid of known strength, followed by alkali of known strength. Residue was filtered, washed with water and organic solvent and burned in a furnace at $525 \pm 10^{\circ} \mathrm{C}$ for 1 hour and fiber content calculated per $100 \mathrm{~g}$ of test sample. The content of the available carbohydrate was determined by the following equation: Carbohydrates per $100 \mathrm{~g}=100-(\mathrm{fat}+$ protein $+\mathrm{ash}+\mathrm{cu})$. Metabolizable energy was calculated following the formula: Energy Kcal per $100 \mathrm{~g}=[9$ * fat $]+$ [4* (protein + carbohydrate) $]$

Mineral Analysis-Estimation of Iron by WONG's Method (Wong 1928). Estimation of Calcium and Magnesium by colorimetric method. All trace minerals were analysed using validated methods on Inductively Coupled Plasma Analyzer (Model: Thermo Fisher I CAP 6300 Radial). Suitable volume of test sample was prepared by acid-digestion and measured against NIST-traceable reference solution. After data interpretation, observations were reported in desired measurement units.

Physico chemical Properties-Density and viscosity of formulated products were analysed in $5 \%$ solution in milk. The $\mathrm{pH}$ of formulated diets was determined using digital $\mathrm{pH}$ meter (Inolab WTW Series 720). The pH meter was first calibrated using buffer of $\mathrm{pH} 4.0$ and 7.0 at room temperature. The sample was then taken in a $100 \mathrm{~mL}$ beaker, stirred and electrode of $\mathrm{pH}$ meter put in it and direct reading from $\mathrm{pH}$ meter was taken when the reading stabilized.

\section{Microbiological assessment of products:}

Total Plate Count: The sample was serially diluted and the dilutions were inoculated by pour-plate technique on agar plates. The plates were incubated at $30^{\circ} \mathrm{C}$ for 72 hours. Isolated colonies were counted and observations reported as $\mathrm{cu} / \mathrm{ml}$ of sample.

Total Coliform: Sample was prepared by adding appropriate volume to the diluting fluid and inoculated in MacConkey broth. Test portion was incubated at $37^{\circ} \mathrm{C}$ for 48 hours. After positive presumptive test, sample was subjected to a series of confirmatory tests for presence or absence of coliform bacteria per $1 \mathrm{~g}$ of tested sample.

E. coli: Sample was prepared by adding appropriate volume to the diluting fluid and inoculated in single-strength MacConkey broth. Test portion was incubated at $37^{\circ} \mathrm{C}$ for 48 hours. Samples showing acid and gas production were inoculated on selective agar plates and after incubation typical E. coli colonies were subjected to confirmatory tests. Observations were reported for presence or absence of E. coli per $1 \mathrm{~g}$ of tested sample.

Staphylococcus aureus: Sample was inoculated in an enrichment medium and incubated at $37^{\circ} \mathrm{C}$. The culture was inoculated separately on Blood agar and Baird-Parker agar and incubated at $37^{\circ} \mathrm{C}$ for 24 hours. Typical colonies were subjected to confirmatory tests and observations reported for presence or absence of S. aureus per $25 \mathrm{~g}$ of tested sample.

Salmonella sp.: Sample was inoculated in a non-selective enrichment broth and incubated at $37^{\circ} \mathrm{C}$ for 20 hours. Aliquot of obtained culture was inoculated in selective enrichment medium and incubated at $42^{\circ} \mathrm{C}$ for 24 hours. Aliquot of obtained culture was inoculated on selective agar plates and incubated at $37^{\circ} \mathrm{C}$ for 
24 to 48 hours. Typical colonies were further subjected to confirmatory tests for presence or absence of Salmonella sp. per $25 \mathrm{~g}$ of tested sample.

Clostridium sp.: Sample was inoculated in Cooked-meat enrichment medium and incubated at $35^{\circ} \mathrm{C}$ for 24 hours. Aliquot of obtained culture was streaked on selective agar plate and incubated for $35^{\circ} \mathrm{C}$ for 18 to 20 hours. Typical colonies were subjected to confirmatory tests for presence or absence of Clostridium sp. per $1 \mathrm{~g}$ of tested sample.

Yeast \& Mould: Serially diluted test sample was inoculated on Yeast Extract Dextrose Chloramphenicol agar plates and incubated at $25^{\circ} \mathrm{C}$ for 3 to 5 days. Isolated colonies were counted and observation reported as $\mathrm{cfu} / \mathrm{ml}$ of tested sample.

Bacillus cereus: Serially diluted test sample was inoculated on Mannitol Egg Yolk Polymyxin agar plates and incubated at $30^{\circ} \mathrm{C}$ for 24 hours. Isolated colonies were subjected to confirmatory tests and observations reported for presence or absence of $B$. cereus per $1 \mathrm{~g}$ of tested sample.

\section{RESULT AND DISCUSSION:}

The present study has evaluated the efficacy of $\mathrm{AH}$ infant mixes that were formulated, standardized, analysed for nutrient composition, physiochemical properties, microbiological quality and sensory attributes.

Palatability of Ayurvedic herb (AH): Nutritious meal needs to be attractive in appearance and palatable because it stimulates appetite. The palatability of the food may be judged on the kind of quality and intensity of impressions. Some of the sensory properties of food are appearance, texture, taste, mouthfeel and acceptability. Palatability depends largely upon the freshness of the food. The mean scores calculated for different sensory attributes of the $\mathrm{AH}$ product was found to range between a minimum of 9.00 to a maximum of
9.7 out of a score of 10.00 . The mean score for appearance was maximum (9.7). The mean score for texture was lowest (9.00). Average mouthfeel score was 9.4. Mean score for taste was found to be 9.5. The overall acceptability score was found to be 9.5 .

\section{Proximate Analysis \\ Macronutrients:}

Good nutrition is essential for the growth and development that occurs during an infant's first year of life. When developing infants are fed the appropriate types and amounts of foods, their health is promoted. For proper growth and development, an infant must obtain an adequate amount of essential nutrients by consuming appropriate quantities and types of food.

The results of proximate analysis are presented in table 1. After the analysis of the moisture free product, the test results showed the protein value as $18.1 \mathrm{~g}$, fat $3.54 \mathrm{~g}$, crude fibre $3.69 \mathrm{~g}$ and total ash $3.65 \mathrm{~g}$ per $100 \mathrm{~g}$. CHO value calculated by difference method was $71.02 \mathrm{~g}$. The energy content of the AH product was $387.70 \mathrm{kcals}$.

Infants need energy from food for activity, growth, and normal development. Energy comes from foods containing carbohydrate, protein, or fat. Carbohydrates serve as primary sources of energy to fuel bodily activities while protein and fat are needed for other essential functions in the body, such as building and repairing tissues. Breast milk and infant formulas provide sufficient protein to meet a young infant's needs if consumed in amounts necessary to meet energy needs. Fat supplies approximately 50 percent of the energy consumed in breast milk and infant formula. Fats allow for the absorption of the fat-soluble vitamins $\mathrm{A}, \mathrm{D}, \mathrm{E}$, and $\mathrm{K}$; and provide essential fatty acids that are required for normal brain development, healthy skin and hair, normal eye development, and resistance to infection and disease. 
Macro Minerals: Macro minerals are needed in larger amounts. Calcium plays an important role in bone and tooth development, blood clotting and maintenance of healthy nerves and muscles. An infant can obtain sufficient calcium by consuming adequate amounts of breast milk or infant formula. Older infants can obtain additional calcium from complementary foods such as yogurt, cheese, fortified or enriched grain products, some green leafy vegetables.

Calcium, and magnesium content of $\mathrm{AH}$ product were $885.84 \mathrm{mg}$ and $86.40 \mathrm{mg}$ per $100 \mathrm{~g}$ of the product respectively.

Magnesium is effective in building stronger bones and teeth. It is good for healthy muscles and nerves and is responsible for enzymatic functions in human body. Magnesium concentration of human milk is about 30 $\mathrm{mg} /$ litre, while infant formulas provide about 40-80 mg/litre and cow's milk approximately $130 \mathrm{mg} /$ litre. In India there are many infants born with low birth weight, a study by Lönnerdal suggest that low birth weight infants may exhibit hypomagnesaemia and benefit from magnesium supplementation.

\section{Trace Elements:}

Trace elements, also known as minor elements are required in minute quantities for proper growth and development and for vital metabolic activities in the human body. Infants are particularly susceptible to metal toxicity because of their immature organs. Aluminium, cadmium and lead are not essential for humans and are known to present risk.

The different trace elements analysed in $\mathrm{AH}$ product is given in table 2. Observation from the table values show that lead, cadmium, arsenic, mercury, tin, chromium, nickel and antimony were not detectable. Iron content of AH was $12.76 \mathrm{mg} / 100 \mathrm{~g}$. Copper and zinc were present. Copper content was negligible. Zinc was found to be slightly higher at $2.88 \mathrm{mg} / 100 \mathrm{~g}$
Iron, is a mineral needed by infants for proper growth and formation of healthy blood cells and prevention of iron-deficiency anaemia. Iron is a vital component of haemoglobin, the part of red blood cells that carries oxygen. Sources of iron for infants include breast milk; infant formula; meat; liver; legumes; whole-grain breads, cereals, or fortified or enriched grain products; and dark green vegetables.

Zinc is a component of many enzymes in the body and is involved in most metabolic processes. Zinc plays a role in general growth and maintenance of all tissues, taste perception and a healthy immune system. Infants obtain zinc from breast milk; infant formula; meat; poultry; liver; egg yolks; cheese; yogurt; legumes; and whole-grain breads, cereals (Institute of Medicine Food and Nutrition Board, 2001).

According to (WHO, 2011) role of Copper and Zinc is evident as Co factors and essential factor for enzyme formation respectively. Prakash $\mathrm{K}$ noted that every day, more than 6,000 children below the age of five die in India more than half of deaths are caused by malnutrition-mainly the lack of Vitamin A, iron, iodine, zinc and folic acid. Zinc is important for bone growth and immunity. The US NIH office of diets supplements lists the effects of copper deficiency which include anaemia, hypopigmentation, hypercholesterolemia, connective tissue disorders, osteoporosis and other bone defects, abnormal lipid metabolism, ataxia, and increased risk of infection. Indian infants are more prone to these conditions and hence supplementation of these elements is necessary in them.

\section{Physico-Chemical Properties-}

The $\mathrm{pH}$ value of mother's milk has been reported to range from $\mathrm{pH} 7$ to 7.4 but never to $\mathrm{pH}$ 4.5. The $\mathrm{pH}$ value of $\mathrm{AH}$ infant mix was found to be 6.68 at $19^{\circ} \mathrm{C}$. 
Viscosity of AH was (5\% Solution in Milk) 1.23 Cst and the density of AH was $0.517 \mathrm{~g} / \mathrm{cc}$. It is essential that a complementary food should have low viscosity, increased solubility, impart desirable sensory characteristics, and potentially avoid excessive energy and nutrient thinning. Amagloh Francis et. al. reported that cereal-based complementary foods from nonmalted ingredients form a relatively high viscous porridge. Therefore, excessive dilution, usually with water, is required to reduce the viscosity to be appropriate for infant feeding. The dilution invariably leads to energy and nutrient thinning, that is, the reduction of energy and nutrient densities. Carbohydrate is the major constituent of food that significantly influences viscosity when heated in water. Viscosity is a key component in the analysis of human milk and infant formulas. Research has shown that viscosity is the most important rheological property to determine the ease of swallowing, especially among preterm infants suffering from dysphagia.

Feeding infant with powdered formula and ready to eat infant food issued from birth through first 2 years to feed millions of infants over the world. This kind of nutrition represents a rich source of nutrients and contains ingredients from various origins. So, it is considered an excellent medium to support bacterial growth and carrying potential risk of exposure to foodborne pathogens. Infants and babies are more susceptible to infection by such pathogens because of their less well-developed immune system and lack of competing intestinal flora.

\section{Microbiological Assay}

Results of microbiological assay of $\mathrm{AH}$ product is shown in table 3. Microbial assays were done at three stages for both the test products. Day 0, Day 15, Day 30 were the point of tests. The TPC at day 30 for $\mathrm{AH}$ was $3.2 \times 10^{2}$ whereas the TPC. No presence of seriously harmful bacteria was found in $\mathrm{AH}$. Initial yeast moulds were $1.6 \times 10^{2}$ and $1.9 \times 10^{2}$ respectively for $\mathrm{AH}$. The Total Viable Count is less than compared to Indian Standards Institute i.e. $<5.0 \times 10^{4} \mathrm{cfu} / \mathrm{g}$ in all the three stages for the AH product in case of yeast and mould. Other harmful bacteria are absent in the foods making it safe for the children to eat.

Malnutrition is the most precipitating factor for disease like diarrhoea in the sub tropics. This is added up by the contaminated food that is fed to the children especially in the poor resource areas. Pathogens like E. Coli are the main culprits which are resulting in mortality of the infants due to disease like diarrhoea coupled with malnutrition.

Complementary food is a rich source of nutrients not only for the child but also to bacteria and other food borne pathogens. Packaged foods are less prone to contamination due to high standards of hygiene and processing that is maintained, reconstituted food has higher susceptibility to contamination. B. cereus was among the primary microbes associated with baby food contamination as reported by WHO Expert Consultations. Prevalence of B. Cereus, a category C or of low risk category pathogen was sufficiently high to cause food borne infection outbreaks in infants. $\mathrm{E}$ coli is responsible for paediatric diarrheal disease and its high morbidity and mortality rates. Staphylococcus aureus is another major bacterium responsible for infant mortality.

However, the $\mathrm{AH}$ product in concern was not contaminated by these microbes rendering it safe to consume. Proper hygiene and storage are mandatory for keeping the food free from infestations.

\section{CONCLUSION:}

Results of the study reflect that the Ayurvedic formula based infant food not only satisfies the palatability aspect but is 
nutrient dense, safe and has a suitable $\mathrm{pH}$ and viscosity. It can serve as a good and economically viable choice as a weaning food for infants.

\section{REFERENCES:}

UNICEF/WHO-World Bank. Joint child malnutrition estimates. New York: UNICEF; Geneva (Switzerland): WHO; Washington (DC): World Bank; 2015.

Goun Jeong, Sung Won Park, Yeon Kyung Lee,Sun Young Ko, Son Moon Shin Maternal food restrictions during breastfeeding, Korean $\mathrm{J}$ Pediatr 2017;60(3):70-76

Victora CG, Adair L, Fall C, Hallal PC, Martorell R, Richter L, Sachdev HS. Maternal and child undernutrition: consequences for adult health and human capital. Lancet 2008; 371:340-57.

Ravi Teja Mandapaka* and Prasanna Kumar K, Processing, Formulation and Market Testing of Nutri Biscuits for Fewer than Threes, Open Access Scientific Reports 2013; 2:4:

Sajilata G, Singhal RS, Kulkarni PR (2002) Weaning foods: a review of the Indian experience, Food Nutr Bull 23: 208226.

Gopaldas T (1991) Technologies to improve weaning foods in developing countries. Indian pediatr 28: 217 221.
Nada A. FATHELRAHMAN, Nour Elhuda A. KHERI, and Isam A. Mohamed ahmed, Development of weaning food from wheat flour supplemented with defatted sesame flour, 2015:16:3.

UNICEF (2012) Infant and young child feeding. Nutrition Section, Programmes, UNICEF New York, USA, $172 \mathrm{p}$.

Preetam Sarkara,Lohith Kumar DH, ChandaDhumala, Shubham SubrotPanigrahi, Ruplal Choudhary, (2015) Traditional and ayurvedic foods of Indian origin, Journal of Ethnic Foods 2 (3) :97109

Meshram II, Mallikharjun Rao K, Ch Gal Reddy et al. Prevalence of Under Nutrition and its Predictors among Under 5 Year Children in Surat Region, Gujarat, India. 2016, J Clin Nutr Diet 2:2. doi: 10.4172/24721921.100009

Fats and Fatty Acids. In: Kleinman RE, ed. Pediatric Nutrition Handbook. 5th ed. Elk Grove Village, IL: American Academy of Pediatrics, 2004:261284.

Lonnerdal B. Effects of milk and milk components on calcium, magnesium, and trace element absorption during infancy. Physiological Reviews, 1997, 77:643-669. 
Vitamin and mineral requirements in human nutrition: report of a joint FAO/WHO expert consultation, Bangkok, Thailand, second edition, 1998. pp $246-272$

Kotecha PV. Micronutrient Malnutrition in India: Let Us Say "No" to it Now. Indian $\mathrm{J}$ Community Med. 2008;33(1):9-10. doi:10.4103/09700218.39235

Amagloh FK, Brough L, Weber JL, Mutukumira AN, Hardacre A, Coad J. Sweetpotato-based complementary food would be less inhibitory on mineral absorption than a maize-based infant food assessed by compositional analysis. Int J Food Sci Nutr. 2012;63(8):957963.

doi:10.3109/09637486.2012.68736 8
Townsend, S., \& Forsythe, S. J. (2007). The neonatal intestinal microbial flora, immunity, and infections. Enterobacter sakazakii, 61-100.

Talukdar PK, Rahman M, Rahman M, Nabi A, Islam Z, Hoque MM, et al. (2013) Antimicrobial Resistance, Virulence Factors and Genetic Diversity of Escherichia coli Isolates from Household Water Supply in Dhaka, Bangladesh. PLoS ONE 8(4): e61090. https://doi.org/10.1371/journal.po $\underline{\text { ne. } 0061090}$

Zeinab I. Sadek, Mohamed Abdel-Rahman, Mohamed S.Azab, Osama M.Darwesh Mahmoud S.Hassan Microbiological evaluation of infant foods quality and molecular detection of Bacillus cereus toxins relating genes, Toxicology Reports, Volume 5, 2018, Pages 871-877.

Table1: Nutritive Value of AH Formulated Infant Food (per 100g)

\begin{tabular}{|c|c|c|c|c|c|c|c|}
\hline $\begin{array}{c}\text { Calories } \\
\text { (kcal) }\end{array}$ & $\begin{array}{c}\text { Protein } \\
\text { (g) }\end{array}$ & $\begin{array}{c}\text { Fat } \\
\text { (g) }\end{array}$ & $\begin{array}{c}\text { CHO } \\
\text { (g) }\end{array}$ & $\begin{array}{c}\text { Crude } \\
\text { fibre (g) }\end{array}$ & $\begin{array}{l}\text { Total } \\
\text { ash(g) }\end{array}$ & $\begin{array}{c}\text { Calcium } \\
\text { (mg) }\end{array}$ & $\begin{array}{c}\text { Magnesium } \\
\text { (mg) }\end{array}$ \\
\hline 387.70 & 18.1 & 3.54 & 71.02 & 3.69 & 3.65 & 885.84 & 86.40 \\
\hline
\end{tabular}


Table no 2: Trace Element Contents of AH Formulated Infant Food (per 100g)

\begin{tabular}{|c|c|c|c|}
\hline Sr no & Toxic Metal & Measurement unit & AH \\
\hline 1 & Lead $(\mathrm{Pb})$ & $\mathrm{mg} / \mathrm{kg}$ & ND \\
\hline 2 & Cadmium $(\mathrm{Cd})$ & $\mathrm{mg} / \mathrm{kg}$ & $\mathrm{ND}$ \\
\hline 3 & Arsenic $(\mathrm{As})$ & $\mathrm{mg} / \mathrm{kg}$ & $\mathrm{ND}$ \\
\hline 4 & Mercury $(\mathrm{Hg})$ & $\mathrm{mg} / \mathrm{kg}$ & $\mathrm{ND}$ \\
\hline 5 & Copper $(\mathrm{Cu})$ & $\mathrm{mg} / \mathrm{kg}$ & 0.265 \\
\hline 6 & Tin $(\mathrm{Sn})$ & $\mathrm{mg} / 100 \mathrm{~g}$ & $\mathrm{ND}$ \\
\hline 7 & Zinc $(\mathrm{Zn})$ & $\mathrm{mg} / \mathrm{kg}$ & 2.88 \\
\hline 8 & Chromium $(\mathrm{Cr}+6)$ & $\mathrm{mg} / \mathrm{kg}$ & $\mathrm{ND}$ \\
\hline 9 & Nickel $(\mathrm{Ni})$ & $\mathrm{mg} / \mathrm{kg}$ & $\mathrm{ND}$ \\
\hline 10 & Antimony $(\mathrm{Sb})$ & $\mathrm{mg} / 100 \mathrm{~g}$ & 12.76 \\
\hline 11, & Iron $(\mathrm{Fe})$ & & \\
\hline
\end{tabular}

Table no.3 Microbiological Assay of AH Formulated Infant Food

\begin{tabular}{|c|c|c|c|c|c|}
\hline \multirow{2}{*}{$\begin{array}{c}\text { Sr } \\
\text { no. }\end{array}$} & Test Parameter & \multirow{2}{*}{$\begin{array}{c}\text { Measurement } \\
\text { Unit }\end{array}$} & $\begin{array}{c}\text { Test Result } \\
\text { (initial) }\end{array}$ & $\begin{array}{c}\text { Test Result (F } \\
15 \text { days) }\end{array}$ & $\begin{array}{c}\text { Test Result (F 30 } \\
\text { days) }\end{array}$ \\
\cline { 5 - 6 } & & AH & AH & AH \\
\hline 1 & Total Plate Count (TPC) & cfu/g & $1.9 \times 10^{2}$ & $2.6 \times 10^{2}$ & $3.2 \times 10^{2}$ \\
\hline 2 & Total coliform & Per g & Absent & Absent & Absent \\
\hline 3 & Escherichia coli & Per g & Absent & Absent & Absent \\
\hline 4 & Staphylococcus aureus & Per g & Absent & Absent & Absent \\
\hline 5 & Salmonella & Per $25 \mathrm{~g}$ & Absent & Absent & Absent \\
\hline 6 & Yeast \&Mould & cfu/g & 1.6 X $10^{2}$ & 2 X $10^{2}$ & 3.6 X 10 \\
\hline 7 & Bacillus cereus & Per g & Absent & Absent & Absent \\
\hline 8 & Clostridium & Per g & Absent & Absent & Absent \\
\hline
\end{tabular}

